\section{Review: hydrolysed milk formula with dietary and environmental restrictions reduces asthma and wheeze in infants with a familial history of atopy}

Ram FS, Ducharme FM, Scarlett J. Cow's milk protein avoidance and development of childhood wheeze in children with a family history of atopy. Cochrane Database Syst Rev 2002;(3):CD003795.

\section{QUESTION: In infants with a familial history of atopy, does dietary avoidance of cows' milk protein prevent asthma and wheeze during the first year of life?}

Source of funding: no external funding.

For correspondence: Dr F S Ram,

Department of Physiological Medicine, St George's Hospital Medical School,

London, UK. fram@sghms.ac.uk

\section{Data sources}

Studies were identified by searching Medline (1966 to Feb 2002), CINAHL (1982 to Feb 2002), EMBASE/ Excerpta Medica (1980 to Feb 2002), UK National Research Register of Trials (up to Feb 2002), the Cochrane Controlled Trials Register (1966 to Feb 2002), bibliographies of identified articles, and by contacting colleagues and experts in the field.

\section{Study selection}

Randomised controlled trials (RCTs) involving children with a familial history of atopy in $\geq 1$ first degree relative were selected if they compared hydrolysed cows' milk formula or soya based formula with feeding with standard cows' milk based formula during the first 4 months of life or longer. In the hydrolysed formula, the protein source from cows' milk was enzymatically hydrolysed and heat denatured resulting in smaller protein molecules with increased digestibility and reduced allergic potential.

\section{Data extraction}

2 reviewers independently extracted data on study quality, patient characteristics, types of feeds and duration, dietary restrictions, and outcome measures, including asthma or wheeze.

\section{Main results}

10 studies met the selection criteria; study duration ranged from 4-12 months. 7 trials evaluated hydrolysed formula for $\geq 4$ months in addition to dietary restrictions and in some cases dust mite reduction measures. Combining data from 3 of these trials showed a reduction in newly diagnosed and ongoing asthma and wheeze during the first year of life in infants receiving hydrolysed formula (table). There was insufficient evidence to suggest that soya based formula reduced the risk of developing asthma or wheeze at any age.

\section{Conclusions}

In infants with $\geq 1$ first degree relative with atopy, hydrolysed milk formula, in combination with dietary restriction and house mite reduction measures, reduces the risk of developing asthma or wheeze during the first year of life. There is insufficient evidence to show that soya based milk formula has any benefit.
Hydrolysed formula $v$ standard cows' milk based formula in infants with a familial history of atopy*

\begin{tabular}{|c|c|c|c|c|}
\hline \multirow{2}{*}{$\begin{array}{l}\text { Outcome ( } 1^{\text {st }} \\
\text { year of life) }\end{array}$} & \multicolumn{2}{|c|}{ Weighted event rates } & \multirow[b]{2}{*}{ RRR (95\% CI) } & \multirow[b]{2}{*}{ NNT (Cl) } \\
\hline & Hydrolysed & Standard & & \\
\hline Asthma or wheeze & $4 \%$ & $9 \%$ & $60 \%(15$ to 81$)$ & 20 (12 to 100$)$ \\
\hline
\end{tabular}

*Abbreviations defined in glossary; RRR, NNT, and $\mathrm{Cl}$ calculated from data in article.

\section{COMMENTARY}

The prevalence of atopic manifestations (eg, asthma and wheeze) has increased in the past 20 years in most countries, ${ }^{1}$ and up to $30 \%$ of the paediatric population is reported to have atopic symptoms. ${ }^{2}$ The systematic review by Ram et al is one of few reviews to consider RCTs related to the development of asthma or wheeze in infants during the first 12 months of life. An earlier review by Baumgartner et al examined atopic manifestions in infants, but not asthma and wheeze specifically. ${ }^{2}$ Their conclusions were similar to those of Ram et al.

The review by Ram et al specifically addressed asthma and wheeze as the primary outcomes of interest. The review included only RCTs and excluded studies where infants were exclusively breast fed. In addition, some important co-interventions were noted, including restrictions to the mother's and infant's diets in one or both study groups.

Of the 3 studies showing statistically significant differences between hydrolysed formula and cows' milk formula, only 2 were double blind, and these studies applied restrictions on the lactating mother's diet and the infant's diet to avoid a range of potential allergenic foods. Furthermore, breastfeeding practices varied, which raises questions about what percentage of mother's milk was provided to the infant and the duration of exposure. The issue of breastfeeding exposure is of concern when attempting to interpret the results of this review because the effects of mother's milk on the infant may be dose dependent. ${ }^{3}$ The beneficial effects of feeding with hydrolysed cows' milk formula may also be underestimated as only 1 study included infants who were not fed any mother's milk. Researchers should collect detailed data about exposure to breast milk during the intervention period and analyse the results accordingly.

Although the number of studies included in this review is small and important co-interventions are present, when provision of mother's milk is not possible and supplemental feeding is required, use of hydrolysed cows' milk formula should be considered for infants with a familial history of atopy.

$$
\begin{array}{r}
\text { Pamela D Hill, RN, PhD, FAAN } \\
\text { Associate Professor } \\
\text { College of Nursing, University of Illinois at Chicago } \\
\text { Chicago, Illinois, USA }
\end{array}
$$

1 Chandra RK. Food hypersensitivity and allergic diseases. Eur J Clin Nutr 2002;56:S54-6.

Baumgartner M, Brown CA, Exl B-M, et al. Controlled trials investigating the use of one partially hydrolyzed whey formula for dietary prevention of atopic manifestations until 60 months of age: an overview using meta-analytical techniques. Nutrition Research

3 Scariati PD, Grummer-Strawn LM, Fein SB. A longitudinal analysis of infant morbidity and the extent of breastfeeding in the United States. Pediatrics 1997;99:e5. 